\title{
Peningkatan Kemampuan Belajar Matematika Dengan Menggunakan Media Rubu' Al-Mujayyab
}

\author{
Muhammad Hidayat \\ Observatorium Ilmu Falak Universitas Muhammadiyah Sumatera Utara \\ (Email:dayatc65@yahoo.com)
}

\begin{abstract}
Abstrak
Penelitian ini bertujuan untuk mengetahui apakah terdapat peningkatan kemampuan belajar matematika dengan menggunakan media Rubu' Al-Mujayyab pada siswa kelas IX SMP Muhammadiyah 48 Medan T.P 2015/2016.

Penelitian ini menggunakan pendekatan kualitatif dan jenis penelitian yang digunakan yaitu penelitian tindakan kelas (Classroom Action Research) dan memiliki beberapa tahap yang merupakan suatu siklus. Agar permasalahan tidak terlalu luas, maka peneliti membatasi penelitiannya pada pelajaran matematika materi kesebangunan dengan menggunakan media Rubu' Al-Mujayyab.

Hasil penelitian ini menunjukkan dengan menggunakan media Rubu' AlMujayyab kemampuan belajar matematika siswa meningkat, hal ini dapat ditunjukkan dengan peningkatan ketuntasan belajar secara klasikal mencapai $54 \%$ pada siklus I meningkat menjadi $70 \%$ Pada siklus II kemudian pada siklus III meningkat menjadi 87\% Karena tingkat ketuntasan secara klasikal yaitu 75\% Sudah terpenuhi, dengan demikian dapat disimpulkan bahwa dengan menggunakan media Rubu' Al-Mujayyab dapat meningkatkan kemampuan belajar matematika siswa kelas IX SMP Muhammadiyah 48 Medan T.P 2015/2016.
\end{abstract}

\section{Kata Kunci: KemampuanBelajarMatematika, Rubu'Al-Mujayyab}

\section{A. Pendahuluan}

Pembelajaran yang efektif adalah proses belajar mengajar yang bukan saja terfokus kepada hasil yang dicapai peserta didik, namun bagaimana proses pembelajaran yang efektif mampu memberikan pemahaman yang baik, kecerdasan, ketekunan, kesempatan dan mutu serta dapat memberikan perubahan prilaku dan mengaplikasikannya dalam kehidupan mereka. ${ }^{1}$ Hasil belajar dari suatu proses pembelajaran dapat dilihat secara langsung, agar hasil belajar dapat dikontrol dan berkembang secara optimal melalui pembelajaran dikelas, maka program pembelajaran tersebut harus dirancang oleh guru dengan memperhatikan berbagai prinsip yang telah terbukti keunggulannya secara empirik.

Pembelajaran efektif juga dapat menciptakan suasana pembelajaran yang menyenangkan sehingga memberikan kreatifitas siswa untuk mampu belajar dengan potensi yang sudah mereka miliki yaitu dengan memberikan kebebasan dalam melaksanakan pembelajaran dengan cara belajarnya sendiri. Di dalam menempuh dan mewujudkan tujuan pembelajaran yang efektif maka perlu dilakukan sebuah cara agar proses pembelajaran yang diinginkan tercapai yaitu dengan cara belajar efektif. Untuk meningkatkan cara belajar yang

\footnotetext{
${ }^{1}$ Sri Esti Wuryani Djiwandono,

Psikologi Pendidikan (Jakarta: PT Grasindo, 2002), h. 226-227
} 
efektif perlu adanya bimbingan dari guru. $^{2}$

Pembelajaran matematika seharusnya melibatkan peserta didik dalam pengajuan masalah dalam kehidupan sehari-hari yang terkait dengan materi matematika agar peserta didik memahami hubungan apa yang dipelajari dengan kenyataan dalam kehidupannya.

Matematika dalam kehidupan sehari-hari maupun dalam berbagai ilmu pengetahuan memiliki arti yang sangat penting bahwa untuk memajukan kecerdasan bangsanya, kekuatan pertahanan negaranya, kemajuan teknologi dan perekonomiannya, diperlukan manusia-manusia yang menguasai matematika. ${ }^{3}$ Matematika merupakan alat efisien dan diperlukan oleh semua ilmu pengetahuan dan tanpa bantuan matematika semua tidak akan menjadi alat kemajuan yang berarti, maka kualitas pembelajaran yang diberikan oleh guru merupakan hal yang penting untuk diperhatikan.Pemilihan model dan media pembelajaran matematika yang tepat akan membuat matematika disukai oleh siswa dan siswa akan lebih memahami pelajaran matematika.

Tugas sebagai guru sekolah adalah bagaimana memilih cara pembelajaran matematika dengan media pembelajaran yang tepat, yaitu media yang sesuai dengan materi pelajaran, diharapkan mata pelajaran matematika menjadi mata pelajaran yang disukai serta kemampuan pemecahan masalah matematika oleh peserta didik dapat meningkat yang pada akhirnya berpengaruh pada hasil belajar

\footnotetext{
${ }^{2}$ Slameto, Belajar dan Faktor - Faktor Belajar yang Mempengaruhi (Jakarta: rineka cipta, 1995), h. 75-76.

$\begin{array}{ccr}3 & \text { E.T } & \text { Ruseffendi,Pengantar } \\ \text { Pembantu } & \text { Guru } & \text { Mengembangkan }\end{array}$

Kompetensinya Dalam Pengajaran Matematika Untuk Meningkatkan CBSA. (Bandung: Tarsito, 1993),h.58
}

disekolah. $^{4}$ Oleh karena itu dalam penelitian ini akan dijelaskan bagaimana penggunaan Media Rubu' Al-Mujayyab dalam pembelajaran matematika.

\section{B. Profil dan Sejarah Rubu' Al- Mujayyab}

\section{Media Rubu'Al-Mujayyab}

Rubu' Al-Mujayyab adalah alat yang bentuknya seperempat lingkaran yang berguna untuk menghitung dan mengukur ketinggian suatu benda. ${ }^{5}$ Sampai saat ini, Rubu'Al-Mujayyab masih digunakan oleh beberapa kalangan umat Islam di Indonesia untuk menghitung dan menentukan arah kiblat dan garis bujur ekliptika dan deklinasi matahari. Rubu' $A l$ Mujayyab merupakan bagian dari program Ilmu Falak yang diajarkan di pesantren tradisional. Bahkan saat ini, Rubu Al-mujayyab yang diproduksi di Indonesia untuk tujuan pendidikan. ${ }^{6}$

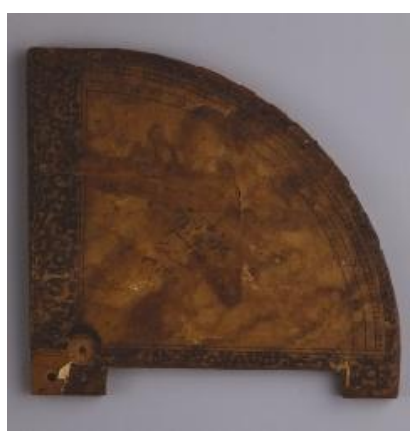

Gambar 1.1: Rubu Mujayyab tahun $1038 \mathrm{M}$ terbuat dari bahan kayu, kulit dan tinta. Ukuran

4 Sugi, Pengaruh Model Pembelajaran Gerlach And Ely Terhadap Kemampuan pemahaman Konsep Matematika Pada Siswa SMA Negeri 10 Medan, (Medan : UMSU,2013), h.3

${ }^{5}$ Encep Abdul Rojak.Hisab Arah

Kiblat Menggunakan Rubu' Mujayyab, (Semarang: IAIN Walisongo Semarang, 2011), h.66

${ }^{6}$ Orchiston,W.,Stephenson,R.,Debarda t,S., and Nha,I.-S(eds).Astronomical Instruments and Archives From the AsiaPasific Region, (Yonsei University Press,Seoul. 2004), h.135 
$12,3 \mathrm{~cm}$, saat ini terdapat di Museum Seni dan Tradisi Fez, Maroko.

Catatan sejarah menunjukkan bahwa periode awal kreasi Rubu'AlMujayyab dimulai sejak abad $3 \mathrm{H} / 9 \mathrm{M}$, tepatnya di kota Bagdad yang bertahan seribu tahun lebih. Selanjutnya Sementara itu di Suriah, alat ini eksis dan terus digunakan sampai abad $3 \mathrm{H} /$ 14 M. Al-Khawarizmi, sang penemu Aljabar, diduga sebagai orang pertama yang menggunakan alat ini. Penggunaan alat ini pada awalnya terbatas pada penentuan waktu berdasarkan posisi matahari. Namun memasuki abad 4 H/ $10 \quad \mathrm{M}$. penggunaannya mulai meluas dan meningkat pada penyelesaian persoalan-persoalan astronomi. Melalui alat ini ditemukan rumusanrumusan mengenai segitiga bola, dengan alat ini pula muncul istilahistilah yang populer di dunia matematika modern seperti sinus, kosinus, tangen, dan kotangen. Fungsi alat ini juga terlihat pada pemecahan masalah-masalah geometri secara numerik. $^{7}$

Bagian-bagian utama sebuah Rubu'AlMujayyab adalah sebagai berikut:

- Markaz : titik pusat rubu yang terdapat lobang kecil yang dipasang padanya seutas benang.

- Qaus Irtifä' : busur utama yang mengelilingi rubu yang diberi skala 0 sampai 90 derajat (dari kanan ke kiri).

- Jaib Tamām : sisi kanan yang menghubungkan markaz ke awal qaus. Jaib tamām diebri skala dari 0 sampai 60 derajat. Tiap-tiap titik satuan skala itu ditarik garis yang lurus sampai

\footnotetext{
${ }^{7}$ Arwin Juli Rakhmadi ButarButar.Khazanah Astronomi Islam Abad Pertengahan (Purwokerto: UM Purwokerto Press 2016), h.364
}

ke qaus. Garis-garis itu disebut juyub al-mankusah. ${ }^{8}$

- Sittīn̄ : sisi kiri yang menghubungkan markaz ke akhir qaus. Bagian ini diberi skala 0 derajat sampai 60 derajat, tiap-tiap titik satuan skala itu ditarik garis lurus menuju ke qaus. Garis itu disebut juyub al-mabsuthah.

- Hadafah : lubang pengintai yang terdapat pada rubu dan posisinya sejajar dengan sittīnī.

- Khaith : benang halus yang dipasang pada markaz.

- Syāqūl : bandul yang dipasang sebagai pemberat khaith.

- Mury : benang pendek yang diikat pada khaith dan dapat digeser naik turun.

- Tajȳ̄b : busur setengah lingkaran dengan radius $1 / 2$ kali radius busur utama. Jika pusat tajyīb terletak di jaib tamam pada jaib 30, maka disebut sebagai tajyz̄b ulā, dan jika pusat tajȳib terletak di sittīn $\bar{\imath}$ pada jaib 30 maka disebut sebagai tajȳīb tsanī.

- Qaus 'ashr : garis lengkung yang ditarik dari awal qaus hingga ke sittīn̄ pada jaib 42,3. Da'irah mail a'zhām : busur berbentuk 1/4 lingkaran yang menggambarkan deklinasi maksimum matahari sebesar $23^{\circ} 27^{\prime}\left(23^{\circ} 45^{\prime}\right)$. $^{9}$

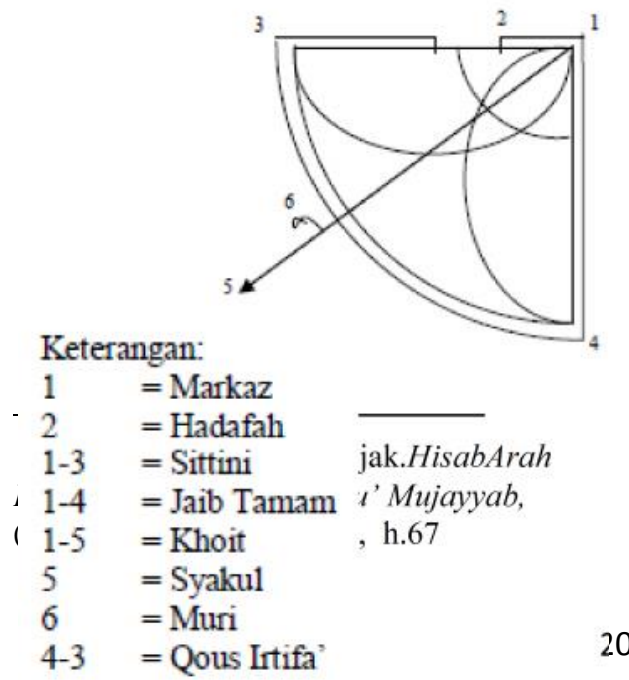


Rubu Al-Mujayab walaupun sederhana, alat ini menyimpan khazanah keilmuan yang luar biasa. Alat ini-bersama instrumen astrolabe terhitung sebagai instrumen astronomi pertama yang muncul di peradaban manusia. Sebelum dikenalnya daftar logaritma, perhitungan astronomi umumnya dilakukan dengan alat ini.

Ibn Syathir (w. 777/1375) adalah salah satu astronom Muslim abad pertengahan yang memiliki sejumlah karya di bidang ini. Ia piawai dalam mengonstruksi alat ini dalam berbagai bentuk. Beberapa karyanya tentang ini antara lain: Kifāyatul Qanū' fìl 'Amal bir Rub'il Maqthū', Risālah fìl 'Amal bi Rub' as Syakāziyyah, Risālah fìl 'Amal bi ar Rub' al Hilāly, Risālatul 'Amal bi Rub' al Jami', an Naf'ul 'Ām fìl 'Amal bi Rub' at Tām li Mawāqūt al Islām, İdhāh al Mughīb fìl 'Amal bir Rub' al Mujayyab, dan lain-lain.Selain itu, Ibn Saraj (w. 714/1314), juga tercatat memiliki kontribusi di bidang rubu mujayyab. Selain itu, Ibn Saraj dan Ibn Syathir, keduanya tercatat pernah melakukan korespondensi dalam mengembangkan alat ini. Dimana Rubu'Al-Mujayyab hasil konstruksi Ibn Saraj pernah dikirim kepada Ibn Syathir guna diperbaiki. Selanjutnya, Ibn Syathir pun memperbaiki dan mengembalikannya kepada Ibn Saraj ${ }^{10}$

$$
\text { Penggunaan Rubu' Al- }
$$

Mujayyab bisa dipasang secara vertikal maupun horizontal tergantung keperluannya $^{11}$. Secara fungsional, Rubu' Al-Mujayyab memiliki tiga fungsi utama yaitu sebagai :

1. Alat Hitung

2. Alat Ukur

\footnotetext{
${ }^{10}$ Arwin Juli Rakhmadi Butar-Butar, Khazanah Astronomi Islam Abad Pertengahan, (Purwokerto: UM Purwokerto Press, 2016), h.364

${ }^{11}$ HendroSetyanto, PetunjukPenggunaanRubu' (Pudak Scientific: Bandung, 2002), h.2
}

\section{Tabel Astronomis. ${ }^{12}$}

Fungsi utama Rubu'Al-Mujayyab adalah sebagai alat hitung sudut atau yang dikenal sebagai ortogonal grid $^{13}$ yang kemudian dapat diolah dengan menggunakan persamaan tertentu yang sesuai dengan kebutuhan pemakai. ${ }^{14}$

\section{Penerapan Media Rubu' Al- Mujayyab terhadap Pembelajaran Matematika \\ Media Rubu' Al-Mujayyab} adalah alat klasik yang akan membantu siswa dalam memahami konsep kesebangunan dan diharapkan dapat meningkatkan kemampuan belajar matematika. Kesebangunan adalah salah satu konsep matematika yang penting untuk dipelajari, karena dalam kehidupan sehari-hari banyak aplikasi tentang konsep kesebangunan, antara lain pembuatan denah atau replika bangunan, pembuatan pola batik, menghitung tinggi bangunan yang tidak terjangkau dan sebagainya. Namun pada kenyataannya sebagian orang khususnya siswa kurang memahami konsep dari kesebangunan, sehingga mereka mengalami kesulitan menyelesaikan soal yang berhubungan dengan konsep kesebangunan. ${ }^{15}$ Berikut adalah syarat kesebangunan.

a. Syarat Dua Bangun Datar Sebangun

Sebangun "Dua bangun datar dikatakan sebangun jika sudut-sudut yang bersesuaian sama besar dan sisi yang bersesuaian sebanding"

\footnotetext{
${ }^{12}$ Ibid, h. 1

${ }^{13}$ Ibid, h.5

${ }^{14}$ Ibid, h. 14

${ }^{15}$ Ayu

Erma KartikaDewi,DarmawanSatyananda, Lathiful Anwar, Pengembangan Media PembelajaranMatematikaBerbantuanKompute rPadamateriKesebangunanUntuksiswakelas IX SM, (Malang :UniversitasNegeri Malang, 2013), h.1
} 

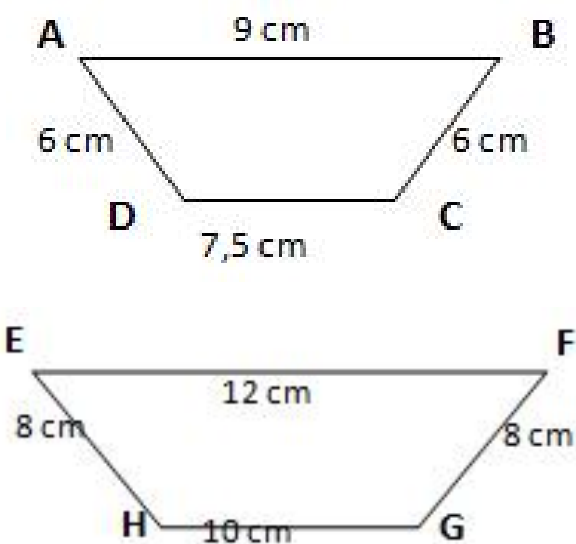

b. Syarat Dua Segitiga Sebangun

Segitiga Sebangun "Jika pada dua segitiga sudut-sudut yang bersesuaian sama besar, maka kedua segitiga itu sebangun"16

$\mathrm{R}$
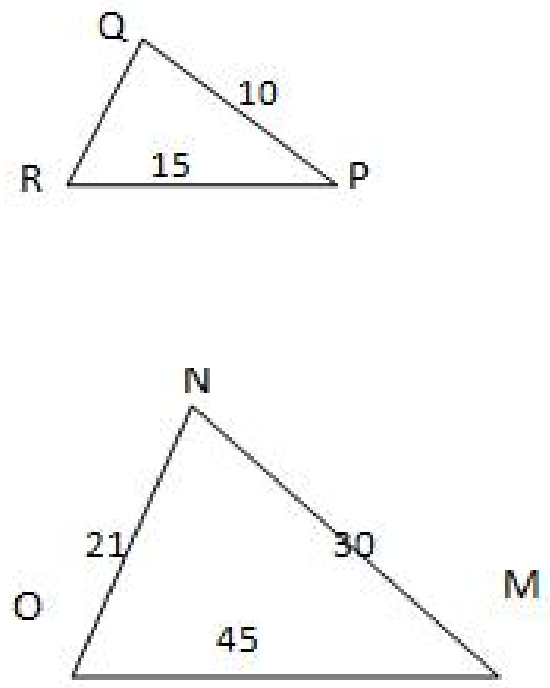

${ }^{16}$ R.Sulaiman,Tatag Yuli Eko S,Toto Nusantara,Kusrini,Ismail,Atik

Wintarti.2008.Contextual Teaching and Learning Matematika:Sekolah Menengah Pertama/Madrasah Tsanawiyah Kelas IX Edisi 4/R. (Jakarta:Pusat Perbukuan, Departemen Pendidikan Nasional, 2008), h.12
Oleh karenanya penerapan materi kesebangunan dengan menggunakan media Rubu' Al-Mujayyab dapat dilakukan dengan tahapan sebagai berikut:

1. Guru mengawali penjelasan materi kesebangunan kepada peserta didik dengan menjelaskan manfaat mempelajari materi tersebut.

2. Guru menjelaskan materi kesebangunan dan operasinya.

3. Guru memperkenalkan media Rubu' Al-Mujayyab kepada peserta didik.

4. Guru menjelaskan konsep kesebangunan yang sering dijumpai di alam sekitar dengan penyelesaiannya menggunakan media Rubu' Al-Mujayyab.

5. Peserta didik diminta untuk membuat replika $R u b u$ ' $A l$ Mujayyab dengan bahan sederhana.

6. Guru bersama peserta didik mempraktekan Rubu' AlMujayyab tersebut terkait dengan penyelesaian konsep kesebangunan.

7. Guru memberikan tugas berkaitan dengan konsep kesebangunan yang sering ditemukan di alam sekitar secara individu. 


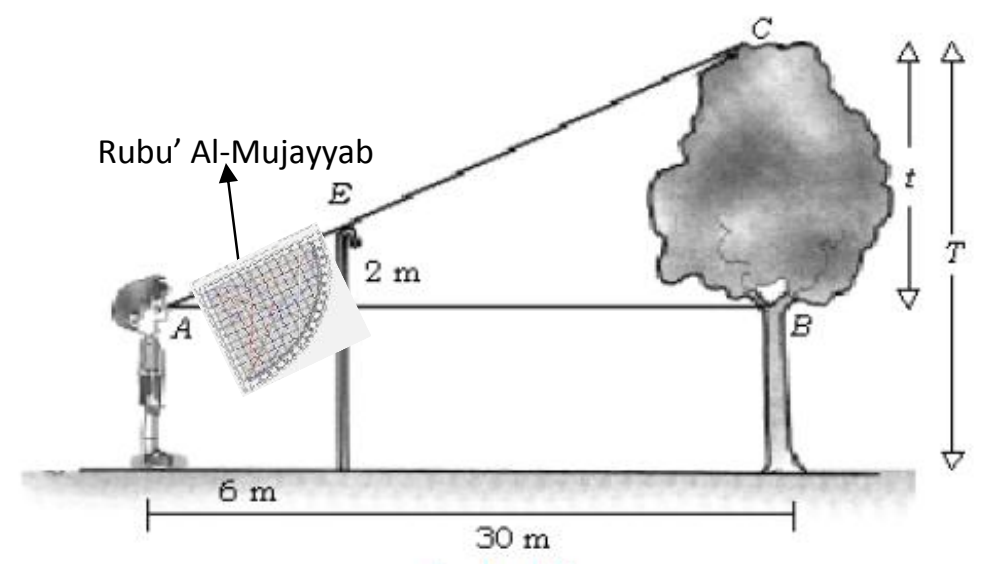

\section{Metodologi}

Contoh penggunaan Rubu' Al-Mujayyab dalam menghitung tinggi pohon.

Jenis penelitian ini adalah

Penelitian tindakan kelas (Classroom Action Research). Pendekatan yang digunakan adalah pendekatan kualitatif yang bertujuan untuk memaparkan proses dan hasil penggunaan media Rubu' Al-Mujayyab dalam upaya meningkatkan kemampuan belajar matematika pada materi kesebangunan. Penelitian ini dilaksanakan di SMP Muhammadiyah 48 Medan, yang berlokasi di Jalan Tangguk Bongkar,Mandala by pass Medan. Waktu penelitian ini dilakukan dari bulan Desember 2015 sampai dengan bulan Maret 2016 di kelas IX SMP Muhammadiyah 48 Medan. Adapun yang akan menjadi subjek penelitian ini adalah siswa kelas IX SMP Muhammadiyah 48 Medan yang berjumlah 32 orang, yang terdiri dari 17 siswa perempuan dan 15 siswa lakilaki. Objek penelitian disini adalah penggunaan media Rubu' AlMujayyab pada pokok bahasan materi Kesebangunan pada siswa SMP Muhammadiyah 48 Medan T.P 2015/2016.

Sesuai dengan jenis penelitian ini yaitu penelitian tindakan kelas maka penelitian ini memiliki bebrapa tahap yang merupakan suatu siklus. Tiap siklus dilaksanakan sesuai dengan perubahan yang akan dicapai. Pada penelitian ini jika siklus I tidak berhasil yaitu proses mengajar tidak berjalan dengan baik maka dilaksanakan siklus II dan seterusnya. Siklus akan berhenti jika penalaran logis matematika siswa telah tuntas secara klasikal.

\section{Hasil dan Pembahasan}

Sebelum pelaksanaan penelitian tindakan kelas dilakukan, terlebih dahulu diadakan tes awal (pre test) kepada siswa yang berjumlah 32 orang, yang terdiri dari 17 siswa perempuan dan 15 siswa laki-lakisebanyak 5 soal untuk mengetahui kemampuan awal siswa sebelum dilaksanakan pembelajaran dengan menggunakan media Rubu' Al-Mujayyab. Setelah hasil tes awal diperoleh tingkat ketuntasan belajar dengan hasil nilai rata-rata siswa sebesar $41 \%$ dari 24,7 orang siswa yang mencapai ketuntasan belajar. Untuk meningkatkan kemampuan belajar matematika siswa, maka dirancanglah dalam suatu siklus, pada awalnya penelitian ini direncanakan akan dilakukan dalam beberapa siklus sampai tujuan penelitian tercapai, ternyata dalam 3 siklus hasil nilai siswa telah mencapaiketuntasan klasikal yang telah ditetapkan yaitu $75 \%$. 


\section{Siklus I}

Pada siklus I materi yang diajarkan adalah Kesebangunan. Siklus ini peneliti melakukan 2 kali pertemuan dengan pertemuan 1 menjelaskan pembelajaran dengan media $R u b u$ ' $A l$ -
Mujayyab sedangkan dalam pertemuan II mengerjakan soal. Tabel berikut akan mendeskripsikan tingkat ketuntasan belajar yang didapat dari model Siklus I.

Tabel 1

Persentase Ketuntasan Tes Kemampuan Belajar Siswa Pada Siklus I

\begin{tabular}{|l|l|}
\hline \multicolumn{2}{|c|}{ Siklus I } \\
\hline Tuntas & $54 \%$ \\
\hline TidakTuntas & $46 \%$ \\
\hline
\end{tabular}

Peningkatan Kemampuan belajar siswa ini belum sesuai dengan tingkat ketuntasan klasikal yang telah ditetapkan yaitu $75 \%$ sehingga perlu diadakan perbaikan dalam siklus II yang dapat memaksimalkan hasil belajar siswa dengan menggunakan media Rubu'Al-Mujayyab.

\section{Siklus II}

Pada siklus II. Materi yang diajarkan adalah Kesebangunan. Pembelajaran dilakukan secara klasikal yang difokuskan pada kesulitankesulitan yang dihadapi siswa seperti alur pengerjaan soal yang tuliskan peserta didik tidak sesuai dengan pembelajaran. Adapun tingkat ketuntasan yang didapat dari Siklus II ini dapat dilihat pada tabel berikut:

Tabel 2

Persentase Ketuntasan Tes Kemampuan Belajar Siswa PadaSiklus II

\begin{tabular}{|l|l|}
\hline \multicolumn{2}{|c|}{ Siklus II } \\
\hline Tuntas & $70 \%$ \\
\hline TidakTuntas & $30 \%$ \\
\hline
\end{tabular}
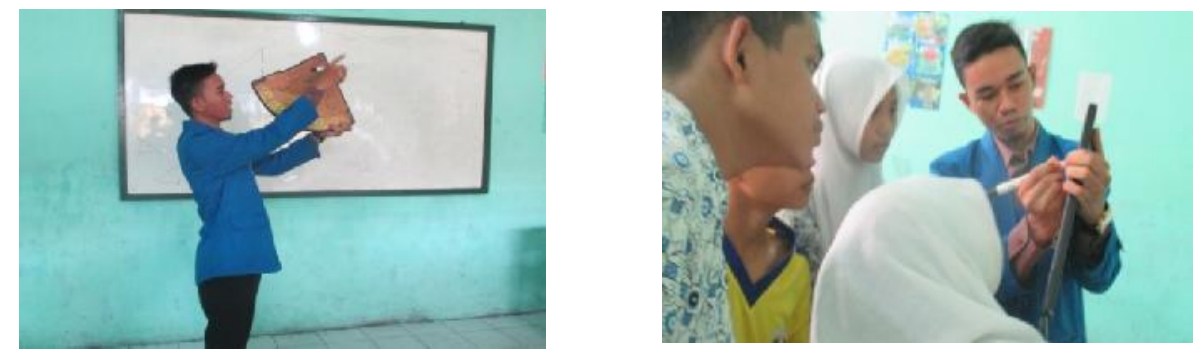

Kegiatan Pembelajaran pada Pelaksanaan Tindakan II (Sumber :DokumentasiPribadi)

Peningkatan Kemampuan belajar siswa pada siklus II ini belum sesuai dengan tingkat ketuntasan klasikal yang telah ditetapkan yaitu $75 \%$ sehingga perlu diadakan perbaikan dalam siklus III yang dapat memaksimalkan hasil belajar siswa dengan menggunakan media Rubu' $\mathrm{Al}$ Mujayyab 


\section{Siklus III}

Pada siklus III. Materi yang diajarkan adalah Kesebangunan. Pembelajaran dilakukan secara klasikal yang difokuskan pada kesulitankesulitan yang dihadapi siswa seperti konsep soal yang tidak bermakna menjadi soal yang lebih dikaitkan pada lingkungan sekitar. Tingkat ketuntasan hasil belajar siswa pada siklus III dapat dilihat pada tabel berikut:

Tabel 3

Persentase Ketuntasan Tes Kemampuan Belajar Siswa Pada Siklus III

\begin{tabular}{|l|l|}
\hline \multicolumn{2}{|c|}{ Siklus III } \\
\hline Tuntas & $87 \%$ \\
\hline TidakTuntas & $13 \%$ \\
\hline
\end{tabular}
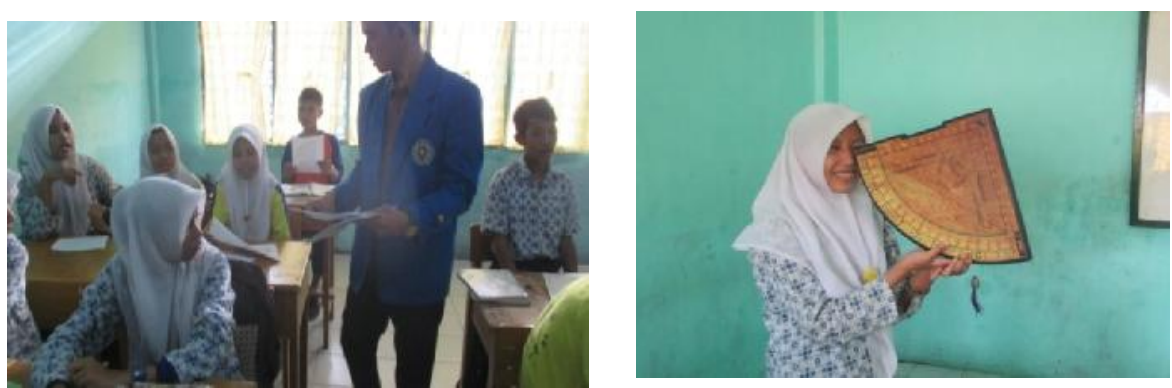

Kegiatan Pembelajaran pada Pelaksanaan Tindakan III (Sumber :DokumentasiPribadi)

Pada siklus III diperoleh tingkat ketuntasan siswa sebesar $87 \%$ Sehingga secara klasikal dinyatakan telah mencapai ketuntasan dalam belajar, sehingga tidak perlu dilanjutkan kesiklus berikutnya.
Tabel

berikut

ini mendeskripsikan nilai rata-rata hasil belajar siswa dari mulai tindakan awal, siklus I, siklus II dan siklus III.

Tabel 4

Nilai Persentase Tes Awal, Siklus I, Siklus II, dan siklus III

\begin{tabular}{|c|l|l|l|l|}
\hline No & HasilTes & $\begin{array}{l}\text { Nilai } \\
\text { Rata-Rata }\end{array}$ & $\begin{array}{l}\text { Ketuntasan } \\
\text { Klasikal }\end{array}$ & Keterangan \\
\hline 1. & TesAwal & 61.66 & $41 \%$ & BelumTuntas \\
\hline 2. & Tes Siklus I & 68.2 & $54 \%$ & BelumTuntas \\
\hline 3. & Tes Siklus II & 74.16 & $70 \%$ & BelumTuntas \\
\hline 4. & Tes Siklus III & 80.62 & $87 \%$ & Tuntas \\
\hline
\end{tabular}

Dari Tabel diatas terlihat nilai rata-rata hasil belajar siswa yang meningkat dari mulai tindakan awal, siklus I, siklus II dan siklus III dan apabila di sajikan dalam bentuk diagram akan terlihat seperti Grafik 
dibawah ini, Pada Siklus III nilai ketuntasan klasikal yang diperoleh yaitu $87 \%$ sehingga Ketuntasan Klasikal sudah terpenuhi.

Grafik Peningkatan Ketuntasan Belajar

Tes Awal, Siklus I, Tes Siklus II, dan Siklus III

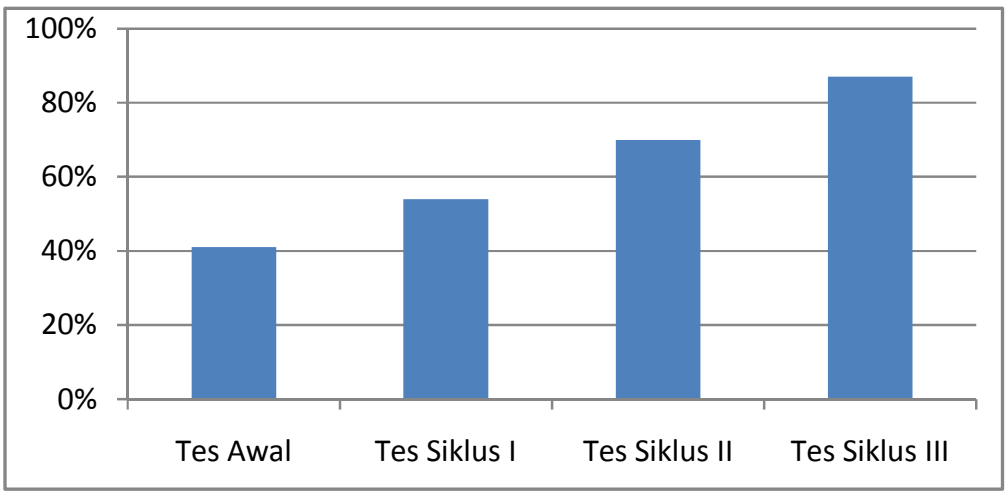

Penelitian ini telah membuktikan bahwa dengan menggunakan media Rubu' Al-Mujayyab dapat meningkatkan kemampuan belajar matematika siswa kelas IX SMP Muhammadiyah 48 Medan T.P 2015/2016. Adapun kelemahan dalam penelitian ini ialah masih sedikitnya capaian tujuan dalam penelitian tersebut. Saran untuk penelitian berikutnya ialah dapat menerapkan media Rubu' Al-Mujayyab dalam pokok bahasan, tujuan, lokasi dan metode penelitian yang berbeda agar dapat menambah khazanah ilmu pengetahuan sehingga pembelajaran di masa akan datang diharapkan dapat lebih baik lagi.

\section{Kesimpulan}

Dari penjelasan di atas menunjukkan bahwa penggunaan media Rubu' Al-Mujayyab dalam pembelajaran matematika tentang kesebangunan dapat meningkatkan kemampuan belajar matematika siswa. Hal ini ditunjukkan dengan peningkatan hasil ketuntasan belajar secara klasikal mencapai $54 \%$ pada siklus I meningkat menjadi $70 \%$ Pada siklus II kemudian pada siklus III meningkat menjadi $87 \%$ Karena tingkat ketuntasan secara klasikal yaitu
$75 \%$ Sudah terpenuhi, dengan demikian dapat disimpulkan bahwa dengan menggunakan media Rubu' $\mathrm{Al}$ Mujayyab dapat meningkatkan kemampuan belajar matematika siswa kelas IX SMP Muhammadiyah 48 Medan T.P 2015/2016.

\section{Daftar Pustaka}

Aunnurrohman.2009. Belajar dan Pembelajaran.Bandung: Alfabeta

Butar-Butar, Arwin Juli

Rakhmadi.2016. Khazanah

Astronomi Islam Abad

Pertengahan.Purwokerto: UM

Purwokerto Press.

Dewi,Ayu Erma Kartika

Dewi.2013.Pengembangan

Media Pembelajaran

Matematika Berbantuan

Komputer Pada Materi

Kesebangunan Untuk Siswa

Kleas IX SMP. Malang.

Esti Wuryani Djiwandono, Sri.2002.

Psikologi Pendidikan Jakarta: PT

Grasindo.

Mohamed,Mohaini.2004.Matematikaw an Muslim Terkemuka.Jakarta:

Salemba Teknika

Orchiston,W.,Stephenson,R.,Debardat, S.,and Nha,I.-S(eds).2004. Astronomical Instruments and 
Archives From the Asia-Pasific

Region. Yonsei University Press,Seoul.

Rojak,Encep Abdul.2011.HisabArah Kiblat Menggunakan Rubu' Mujayyab. Semarang

Setyanto, Hendro. 2002. Petunjuk

Percobaan Guru Rubu' Al-

Mujayyab, Bandung: Pudak Scientific.

Slameto. 1995.Belajar dan Faktor Faktor Belajar yang Mempengaruhi. Jakarta: rineka cipta.
Sugi.2013.Pengaruh Model Pembelajaran Gerlach And Ely Terhadap Kemampuan pemahaman Konsep Matematika Pada Siswa SMA Negeri 10 Medan,Medan : UMSU

Sulaiman.R,Tatag Yuli Eko S,Toto Nusantara,Kusrini,Ismail,Atik

Wintarti.2008. Contextual Teaching and Learning Matematika:Sekolah Menengah Pertama/Madrasah Tsanawiyah Kelas IX Edisi 4/R.Jakarta:Pusat Perbukuan, Departemen Pendidikan Nasional. 